\title{
A COMPARATIVE STUDY OF EARLY REMOVAL VERSUS CONVENTIONAL PRACTICE OF FOLEY'S CATHETER REMOVAL AFTER TRANSURETHRAL RESECTION OF PROSTATE
}

\author{
Manjuprasad G. B1, Ravikumar Jadhav², Sujit Betageri ${ }^{3}$ \\ ${ }_{1}^{1}$ Associate Professor, Department of Urology, KIMS, Hubli. \\ ${ }^{2}$ Associate Professor, Department of Urology, KIMS, Hubli, \\ 3Junior Resident, Department of General Surgery, KIMS, Hubli.
}

\section{BACKGROUND}

ABSTRACT

Benign prostatic hyperplasia is a common cause of concern in most of the elderly men because of the morbid problems that it gives rise to and is of great concern especially because of the problems of obstructive uropathy, which may in turn bother the clinician with added complications like hydroureteronephrosis. Transurethral resection of prostate remains the gold standard treatment for benign prostatic hyperplasia. The length of hospital stay of patients undergoing TURP, however, is greater. Post-operative care of transurethral resection of the prostate (TURP) includes prolonged bladder irrigation that immobilises patient for long hours. The presence of catheter for many days increases the chances of infection, stricture formation and is also a handicap in day-to-day activities of the patients. This also places the patient on financial loss, as the long hospital stay prevents him to attend to his work.

This study is intended to explore the feasibility and safety of early catheter removal (on day 2) after transurethral resection of prostate as compared with conventional $4^{\text {th }}-5^{\text {th }}$ day catheter removal.

\section{MATERIALS AND METHODS}

The study was a prospective hospital-based time-bound non-randomised controlled trial conducted between November 2015 and November 2017 at a Medical College Hospital. 35 patients with benign prostatic hyperplasia were included in the study. Patients were divided into two groups using alternate allocation method. 18 patients were included in the early removal group and 17 patients were included in the late removal group. Catheters of patients in the early removal group were removed on POD-2 of surgery and other 17 patients who belonged to the late removal group underwent catheter removal on POD-4 or POD-5. After removal of catheter, the patients were observed, and outcomes were carefully recorded.

\section{RESULTS}

Length of post-operative hospital stay was significantly shorter in patients who underwent early catheter removal after TURP. No significant difference in the rate of complications was seen in between the groups.

\section{CONCLUSION}

Our study suggests that in most of the patients who undergo TURP and who do not have any significant per operative complications, early removal of catheter after a short irrigation period is feasible, improves quality of life and is cost effective without significantly increasing post-operative complications.

\section{KEYWORDS}

International Prostate Symptom Score, Benign Prostatic Hyperplasia, Transurethral Resection of Prostate, Catheter Removal, Retention of Urine.

HOW TO CITE THIS ARTICLE: Manjuprasad GB, Jadhav R, Betageri S. A comparative study of early removal versus conventional practice of Foley's catheter removal after transurethral resection of prostate. J. Evolution Med. Dent. Sci. 2018;7(19):2313-2316, DOI: $10.14260 /$ jemds/2018/521

\section{BACKGROUND}

Benign prostatic hyperplasia (BPH) is one of the common ailments that affects elderly men.(1) It is the common cause of concern in most of the elderly men, because of the morbid problems that it gives rise to and is of great concern especially because of the problems of obstructive uropathy, which may in turn bother the clinician with added complications like hydroureteronephrosis.

'Financial or Other Competing Interest': None.

Submission 15-12-2017, Peer Review 16-01-2018,

Acceptance 22-01-2018, Published 07-05-2018.

Corresponding Author:

Dr. Sujit Betageri,

\#UGF-2, First Floor

Namma Mane Apartments,

Veeranagouda Patil Layout,

Behind Amrut Talkies, Vidyanagar, Hubli.

E-mail: drsujit.betageri@gmail.com

DOI: $10.14260 /$ jemds $/ 2018 / 521$
Lower urinary tract symptoms (LUTS)(2) refer to a group of clinical symptoms involving the bladder, urinary sphincter, urethra and the prostate. LUTS include obstructive and irritative symptoms. Obstructive symptoms result from impaired detrusor contractility and increased urethral resistance, whereas irritative symptoms are due to detrusor instability or decreased compliance. The International Prostate Symptom Score (IPSS) is recommended as the symptom scoring instrument to be used for the baseline assessment of symptom severity in men presenting with LUTS.(3,4) It consists of seven questions referring to LUTS as in AUA symptom index with an additional question referring to quality of life. When the IPSS system is used, symptoms can be classified as mild ( 0 to 7 ), moderate ( 8 to 19 ) or severe (20 to 35).

A number of methods of treatment of bladder outflow obstruction have been proposed over the years, but transurethral prostatectomy remains the gold standard by 
which all others must be judged. Transurethral resection of the prostate has been reported to represent more than $30 \%$ of the workload of urologists and remains the dominant major procedure performed by urologists.

The length of hospital stay of patients undergoing TURP, however, is greater. Post-operative care of transurethral resection of the prostate (TURP) includes prolonged bladder irrigation that immobilises patient for long hours. The presence of catheter for many days increases the chances of urinary tract infection, stricture formation and is also a handicap in day-to-day activities of the patients. This also places the patient on financial loss, as the long hospital stay prevents him to attend to his work.

Though, traditionally the catheter is removed at around 4 days post-TURP, there is little or no mention of the exact duration of catheterisation following TURP in literature. ${ }^{9}$

This study was intended to explore the feasibility and safety of early catheter removal (on day 2) after transurethral resection of prostate as compared with conventional $4^{\text {th }}-5^{\text {th }}$ day catheter removal.

\section{Aims and Objectives}

1. To assess the safety and feasibility of catheter removal on POD-2 after TURP.

2. To know whether the early removal of catheter in postTURP patients will be beneficial when compared to the conventional $4^{\text {th }}$ day catheter removal.

3. To compare the morbidities associated with conventional practice wherein the catheter is removed 4-5 days after surgery and early removal wherein the catheter is removed within 2 days of surgery.

\section{MATERIALS AND METHODS}

The study was a prospective non-randomised controlled trial conducted between November 2015 and November 2017 at a medical college hospital. Patients were placed alternately in either the early removal or the late removal group. The first patient was put into late removal group and second patient in early removal group. The third patient was placed again in the late removal group and so on. In the first (early removal) group, the catheter was removed on POD-2 after surgery. In the second (late removal) group, the catheter was removed on 4 th (or $5^{\text {th }}$ ) day after surgery.

All patients of benign prostatic hyperplasia (BPH), whose symptoms were longstanding, not relieved by medical line of management, who had at least one failed trial to void and underwent Transurethral Resection of Prostate (TURP) were included in the study.

Patients whose symptoms were relieved by medical line of management, patients with prostate cancer, bleeding diathesis or on anticoagulant therapy, significant medical illness that would increase the anaesthetic risk were excluded from the study. Patients were evaluated with a detailed history and complete physical examination. All routine investigations including renal function tests, urine analysis and culture, ultrasonography to evaluate prostate size and post void residual volume and pre-anaesthetic check were done. TURP was performed with a $26 \mathrm{~F}$ resectoscope with routine precautions to achieve maximum haemostasis. Data of both groups were compared and analysed for statistical significance with Chi-square test and Student ' $\mathrm{t}$ ' test using IBM SPSS Statistics version 20 software.

\section{RESULTS}

Our study included patients between age 50 - 85 years. The youngest patient being 50 years and the oldest being 82 years old. The maximum incidence of the disease was in the age group of 61 - 70 years (46\%). Majority of patients had nocturia that was present in 27 out of 35 patients $(77 \%)$. The second most common mode of presentation was poor stream of urine that was present in 26 out of 35 patients (74\%). Frequency of micturition was the third most common symptom which was seen in 24 out of 35 patients $(69 \%)$. Urgency was present in $22(63 \%)$, retention of urine, straining dysuria were present in 19 (54\%), incomplete emptying in 17 (50\%), dribbling in 13 (37\%), hesitancy in 11 (31\%), urgency incontinence in $9(25 \%)$, intermittent stream and haematuria in 6 patients (17\%). 17 of 35 patients had comorbid conditions in the form of Hypertension 7 (20\%), Diabetes Mellitus 3 (8.6\%), COPD 2 (6\%) and Epilepsy in 1 $(2.8 \%)$ patient. The average IPSS score at presentation was 24.66 in early and 23.01 in late removal groups. Majority of patients $29(83 \%)$ had severe symptoms and rest of the patients had moderate $6(17 \%)$ symptoms according to IPSS grading at presentation. 03 out of 35 patients studied had Grade 1 prostatomegaly, 22 patients had grade 2, 09 patients had grade 3 and 1 patient had grade 4 prostatomegaly on digital rectal examination. Most of the patients 17 (50\%) had prostate volume between 31 and 50 grams, 10 (28.5\%) patients had between 51 - 75 grams and $8(22.8 \%)$ patients had prostate volume more than 75 grams.

$2(5.71 \%)$ patients in early removal group developed retention of urine and $2(5.71 \%)$ patients in late removal group developed retention of urine after catheter removal who needed to be re-catheterised. 2 (5.71\%) patients in early removal group and $1(2.86 \%)$ patient in late removal group were discharged with catheter. These patient's catheters were removed on an outpatient basis around 7 days later. No statistically significant increase in re-catheterisation rate was noted in the early removal group, which suggested that retention of urine did not develop as a result of early removal of catheter after TURP.

In the post-operative period, average post void residual volume in the early removal group was $14.77 \mathrm{~mL}$ as compared to $12.52 \mathrm{~mL}$ in the late removal group. There was no statistical significance noted in both the groups.

The average improvement in IPSS at 1 month after surgery was $9.56(27.31 \%)$ and at 3 months it was 7.74 $(22.11 \%)$. No statistically significant difference was noted in both the groups.

The average duration of hospital stay after surgery for early removal group was 3.72 days and in the late removal group it was 5.23 days. Length of post-operative hospital stay was significantly shorter $(P<0.001)$ in patients who underwent early catheter removal after TURP. This could be translated into early mobilisation of patients, lesser postoperative pain, early discharge and reduced cost burden on the hospital. Also, there was reduced incidence in urinary tract infections in early removal group, which may indicate reduced risk of urethral strictures in future. 


\begin{tabular}{|c|c|c|}
\hline Incidence of UTI & Early Removal & Late Removal \\
\hline $\begin{array}{c}\text { UTI after Catheter } \\
\text { Removal }\end{array}$ & 03 & 06 \\
\hline Percentage & 8.57 & 17.14 \\
\hline \multicolumn{3}{|c|}{ UTI after Catheter Removal } \\
\hline
\end{tabular}

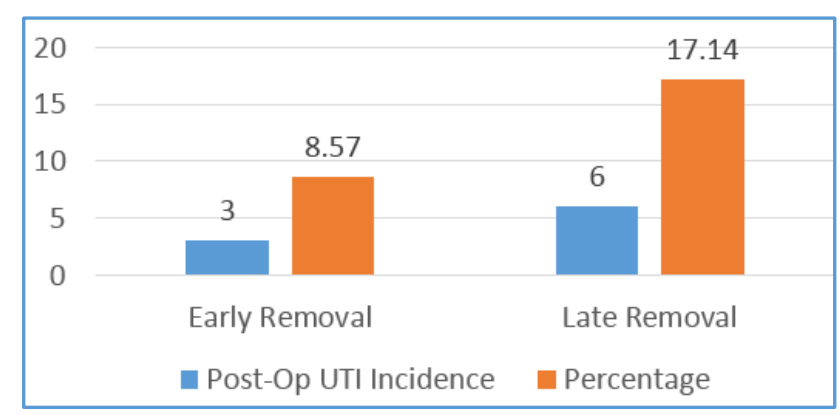

Average Post Void Residual Volume

\begin{tabular}{|c|c|c|}
\hline PVR & $\begin{array}{c}\text { Early } \\
\text { Removal }\end{array}$ & $\begin{array}{c}\text { Late } \\
\text { Removal }\end{array}$ \\
\hline $\begin{array}{c}\text { Post Void Residual } \\
\text { Volume (mL) }\end{array}$ & 14.77 & 12.52 \\
\hline Mean \pm SD & $14.77 \pm 11.68$ & $12.52 \pm 14.02$ \\
\hline \multicolumn{3}{|c|}{ Post-Operative } \\
\hline
\end{tabular}

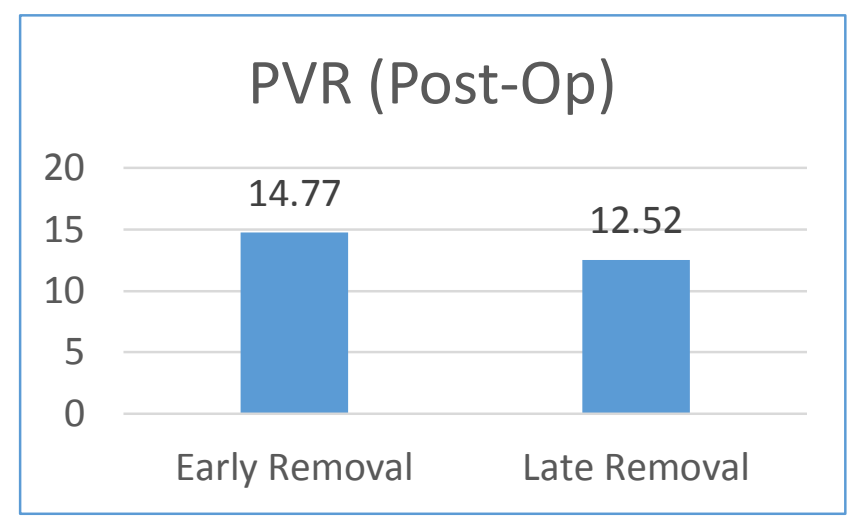

Early Removal: $14.77 \pm 11.68 \mathrm{~mL}$, Late Removal: $12.52 \pm 14.02 \mathrm{~mL}, P=0.61$

\begin{tabular}{|c|c|c|}
\hline $\begin{array}{c}\text { Duration of } \\
\text { Post-Op Stay }\end{array}$ & Early Removal & Late Removal \\
\hline $\begin{array}{c}\text { Mean Duration of } \\
\text { Hospital Stay (Days) }\end{array}$ & 3.72 & 5.23 \\
\hline Range (Days) & $3-6$ & $4-7$ \\
\hline Mean \pm SD & $3.72 \pm 0.82$ & $5.23 \pm 1.03$ \\
\hline \multicolumn{2}{|c|}{ Duration of Hospital Stay after Surgery } \\
\hline
\end{tabular}

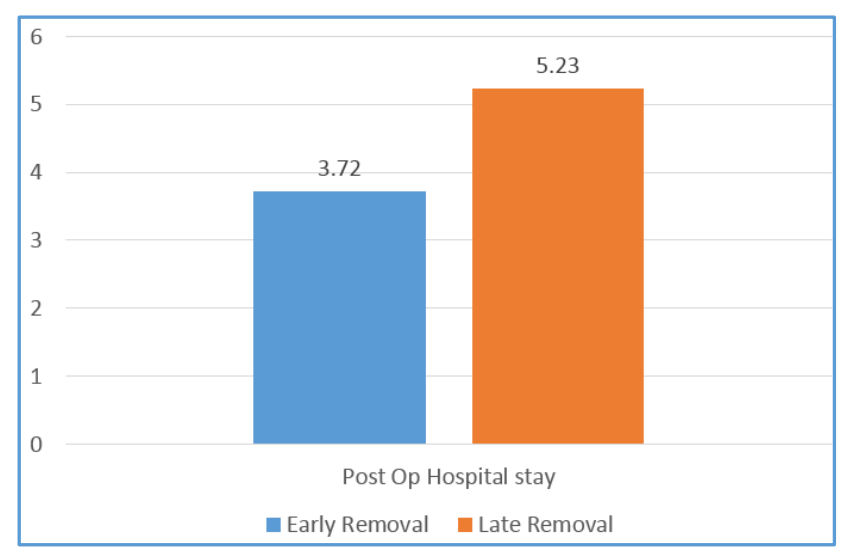

$\mathrm{P}<0.001$

\begin{tabular}{|c|c|c|c|}
\hline Parameter & $\begin{array}{c}\text { Early } \\
\text { Removal } \\
\text { Group }\end{array}$ & $\begin{array}{c}\text { Late } \\
\text { Removal } \\
\text { Group }\end{array}$ & P value \\
\hline Catheter removal & 18 & 17 & \\
\hline $\begin{array}{c}\text { Age (years) } \\
\text { Mean } \pm \text { SD }\end{array}$ & $66.5 \pm 9.5$ & $65.7 \pm 7.79$ & $0.79 \dagger$ \\
\hline Median & 66 & 65 & \\
\hline $\begin{array}{c}\text { Hospital Stay after } \\
\text { Surgery (days) } \\
\text { Mean } \pm \text { SD }\end{array}$ & $3.72 \pm 0.82$ & $5.23 \pm 1.03$ & $<0.001 \dagger$ \\
\hline Median & 04 & 05 & $0.61^{\Phi}$ \\
\hline Comorbidities & 08 & 09 & $0.51^{\Phi}$ \\
\hline $\begin{array}{c}\text { Urinary Retention } \\
\text { requiring Re- } \\
\text { Catheterisation }\end{array}$ & 01 & 02 & $0.31^{\Phi}$ \\
\hline $\begin{array}{c}\text { Haematuria } \\
\text { requiring Re- } \\
\text { Catheterisation }\end{array}$ & 01 & NONE & $0.58^{\Phi}$ \\
\hline $\begin{array}{c}\text { Discharged } \\
\text { with Catheter }\end{array}$ & 02 & 01 & ----- \\
\hline Return to Surgery & None & None & \\
\hline
\end{tabular}

† Unpaired student's t test, ${ }^{\Phi}$ Chi-square test, Statistics calculated using IBM SPSS Statistics Version 20 software.

\section{DISCUSSION}

In our study, maximum incidence of benign prostatic hyperplasia was seen on an average in the sixth decade of life. This group contained 15 patients, which comprised $45.7 \%$ of total patients. The youngest patient in our study was of 50 years and oldest was 82 years. Age specific incidence in our study can be compared with the study of Glynn RJ et al.(5) Average age of presentation in our study was 66.1 years, which is comparable with Gordon et al(6) and Mamo GJ et al,(7) where the average age of presentation was 68.7 years and 69.8 years respectively.

The mean volume of prostate tissue resected (18.12 gm) in our study was higher than that reported by Gordon et al(6) (12.5 gm). However, it was lesser to a study by Chander et $\mathrm{al},(8)$ which reported a mean resection weight of $22.1 \mathrm{gm}$.

The duration of catheterisation after TURP depended primarily on the colour of the catheter effluent. As there was either a clear or lightly tinged effluent at the end of TURP, the duration of catheterisation was 2 days in 18 patients. This is comparable to the study by Srinivasan et al,(9) in which the mean duration of catheterisation in POD-2 group was 48 hours.

The mean duration of hospital stay in our study was 3.72 days. Kirollos(10) carried out a departmental audit of the factors affecting the inpatient stay for elective transurethral resection of the prostate. He concluded that the largest avoidable factors in protracted hospital stay are social reasons for delayed discharge. This appears to hold good in our study also. In his study, the mean hospital stay was 6.4 days.

Except for re-catheterisation, there were no significant early complications noted in our study. Re-catheterisation was needed in $11.42 \%$ patients in our study, which was comparable with $12 \%-14 \%$ of patients requiring recatheterisation in the study by Dodds et al.(11) There were no cases of TUR syndrome or capsular perforation in our study. One patient in the early removal group needed readmission for persistent haemorrhage, which was most likely due to inadequate intra-op haemostasis and was effectively 
managed conservatively. The incidence of headache after spinal anaesthesia or of hypotension was nil, because finebore spinal needles was used in all cases.

No patient in either groups developed any late complications like stricture urethra or bladder neck contracture. Muzzonigro et al(12) reported a 1.8\% stricture rate after TURP and Venrooij et al(13) reported $2.27 \%$ stricture rate.

Patients were followed up on first month and third month after surgery. IPSS score improved from 24.67 preoperatively to 10 at first month and 7.55 at third month, which is comparable to the study by Muzzonigro et al.(12)

\section{CONCLUSION}

Our study suggests that in most of the patients who undergo TURP and who do not have any significant per operative complications, early removal of catheter after a short irrigation period is feasible, improves quality of life and is cost effective, without significantly increasing post-operative complications.

\section{REFERENCES}

[1] Netto NR, de Lima ML, Netto MR, et al. Evaluation of patients with bladder outlet obstruction and mild International Prostate Symptom Score followed up by watchful waiting. Urology 1999;53(2):314-6.

[2] Abrams P. New words for old: lower urinary tract symptoms for "prostatism". BMJ 1994;308(6934):92930.

[3] Kaplan SA. Update on the American Urological Association Guidelines for the treatment of benign prostatic hyperplasia. Rev Urol 2006;8(Suppl 4):S10S17.

[4] Abrams P, Chapple C, Khoury S, et al. Evaluation and treatment of lower urinary tract symptoms in older men. J Urol 2009;181(4):1779-87.
[5] Glynn RJ, Campion EW, Bouchard GR, et al. The development of BPH among the volunteers in normative aging study. Am J Epidemiology 1985;121(1):78-90.

[6] Gordon NS. Catheter-free same day surgery transurethral resection of the prostate. J Urol 1998;160(5):1709-12.

[7] Mamo GJ, Cohen SP. Early catheter removal versus conventional practice in patients undergoing transurethral resection of prostate. Urology 1991;37(6):519-22.

[8] Chander J, Vanitha V, Lal P, et al. Transurethral resection of the prostate as catheter-free day-care surgery. Brit J Urol Int 2003;92(4):422-5.

[9] Srinivasan BK, Radhakrishnan R. Prospective study on removal of urethral catheter on post op day 2 vs conventional day 4 after Turp. Journal of Dental and Medical Sciences (IOSR-JDMS) 2015;14(5):30-2.

[10] Kirollos MM. Length of postoperative hospital stay after transurethral resection of prostate. Ann R Coll Surg Engl 1997;79(4):284-8.

[11] Dodds L, Lawson PS, Crosthwaite AH, et al. Early catheter removal: a prospective study of 100 consecutive patients undergoing transurethral resection of the prostate. Br J Urol 1995;75(6):755-7.

[12] Muzzonigro G, Milanese G, Minardi D, et al. Safety and efficacy of transurethral resection of prostate glands up to $150 \mathrm{ml}$ : a prospective comparative study with 1 year of follow up. J Urol 2004;172(2):611-5.

[13] Van Venrooij GE, Van Melick HH, Eckhardt MD, et al. Correlations of urodynamic changes with changes in symptoms and well-being after transurethral resection of the prostate. J Urol 2002;168(2):605-9. 